\title{
DIVERSIDADE GENÉTICA EM CASTANHEIRA- DO-GURGUEIA (Dipteryx lacunifera DUCKE) COM BASE EM CARACTERÍSTICAS FÍSICAS E QUÍMICO-NUTRICIONAIS DO FRUTO ${ }^{1}$
}

\author{
FRANCISCA SAMARA DE CARVALHO RIBEIRO², \\ VALDOMIRO AURÉLIO BARBOSA DE SOUZA ${ }^{3}$, ÂNGELA CELIS DE ALMEIDA LOPES ${ }^{4}$
}

RESUMO - Este estudo teve como objetivo avaliar a divergência genética entre 23 genótipos de castanheirado-gurgueia, com base em características físicas e químico-nutricionais do fruto. Os frutos foram coletados em áreas de ocorrência natural da espécie no cerrado do sudoeste piauiense. As características físicas analisadas foram: (a) fruto - massa média (MMF); comprimento (CF); largura (LF); espessura (EF), e massa média do pericarpo (MMP); e (b) castanha - massa média (MMC); comprimento (CC); largura (LC), e espessura (EC). As características químico-nutricionais da castanha analisadas foram: gordura $(\mathrm{G})$; proteína bruta (PB); fibra bruta (FB); cinzas (CZ); carboidratos totais (CT); energia (E), e minerais (P, K, Ca, Mg, Mn, $\mathrm{Fe}, \mathrm{Cu}$ e $\mathrm{Zn}$ ). A divergência genética foi estimada utilizando a distância generalizada de Mahalanobis $\left(\mathrm{D}^{2}\right)$ como medida de dissimilaridade. Estimou-se, também, a importância relativa das características na divergência genética. Os métodos de agrupamento utilizados foram de Tocher e UPGMA. Os genótipos apresentaram variabilidade para a maioria das características analisadas. Os genótipos G-17 e G-18 são os mais divergentes, e os genótipos G-3 e G-16 são os mais similares. As características que tiveram as maiores contribuições para a divergência entre os genótipos foram MMP, MMF, E, FB, CT e PB. A castanha-do-gurgueia é uma boa fonte de P, K, Mg, PB, FB, CT e E.

Termos para indexação: Castanha, análise multivariada, cerrado piauiense.

\section{GENETIC DIVERSITY IN CASTANHEIRA-DO-GURGUÉIA (Dipteryx lacunifera DUCKE) BASED ON FRUIT PHYSICAL, CHEMICAL AND NUTRITIONAL CHARACTERISTICS}

\begin{abstract}
This study aimed to evaluate the genetic divergence among 23 "castanheira-do-gurguéia" genotypes based on fruit physical, chemical and nutritional characteristics. Fruits were collected from natural occurrence areas of the Piauí southwestern savannah. The physical characteristics analyzed were: (a) fruit average mass (MMF), length (CF), width (LF), thickness (EF) and pericarp average mass (MMP); and (b) nut - average mass (MMC); length (CC), width (LC) and thickness (EC). The nut chemical and nutritional characteristics analyzed were: fat, crude protein, crude fiber, ash and total carbohydrates, all expressed in percentage; crude energy, expressed in kcal $100 \mathrm{~g}^{-1}$, and the minerals ( $\mathrm{P}, \mathrm{K}, \mathrm{Ca}, \mathrm{Mg}, \mathrm{Mn}, \mathrm{Fe}, \mathrm{Cu}$ and $\mathrm{Zn}$ ), expressed in $\mathrm{mg} 100 \mathrm{~g}^{-1}$. The genetic divergence was evaluated using Mahalanobis distance as dissimilarity measure and evaluated the relative importance of the characteristics in the genetic divergence. Tocher and UPGMA grouping methods were used. A high variability for these characteristics was observed among genotypes. The genotypes G-17 and G-18 are the most divergent and the genotypes G-3 and G-16 are the most similar. The characteristics that had the greater contributions to the genetic divergence among genotypes were MMP, MMF, E, FB, CT and PB. The "castanha-do-gurguéia" is richer in P, $\mathrm{K}, \mathrm{Mg}, \mathrm{PB}, \mathrm{FB}, \mathrm{CT}$ and $\mathrm{E}$. Index terms: Nut, multivariate analysis, savannah of the state of Piauí.
\end{abstract}

\footnotetext{
${ }^{1}$ (Trabalho 134-11). Recebido em: 20-04-2011. Aceito para publicação: 27-10-2011. Parte da dissertação de mestrado da primeira autora.

${ }^{2}$ Bióloga, Mestre em Desenvolvimento e Meio Ambiente - MDMA (PRODEMA/TROPEN), Universidade Federal do Piauí, Campus Universitário Petrônio Portela, CEP. 64049-550, Teresina-PI. E-mail: fsamcarvalho@yahoo.com.br ${ }^{3}$ Pesquisador A da Embrapa Meio-Norte, Av. Duque de Caxias, 5650, CEP 64006-220, Teresina-PI (in memoriam) ${ }^{4}$ Professora Titular do Departamento de Biologia, Universidade Federal do Piaú, Av. Universitária, 1310, CEP 64049-550, TeresinaPI. E-mail: acalopes@ufpi.br
} 


\section{INTRODUÇÃO}

O cerrado é um grande repositório de espécies frutíferas nativas com potencial de uso pelo homem, muitas das quais já com vasta exploração por meio do extrativismo, como é o caso do pequi (Caryocar brasiliense Camb.), jatobá (Hymenaea stigonocarpa Mart.), baru (Dipteryx alata Vog.), cagaita (Eugenia dysenterica DC), mangaba (Hancornia speciosa Gomes) e araticum (Annona crassiflora Mart.) (SILVA et al., 2001). Contudo, até o presente, estudos científicos envolvendo espécies frutíferas do cerrado e, especificamente, do cerrado do Meio-Norte, ainda são escassos. Quando se trata de espécies frutíferas ainda pouco conhecidas, como é o caso da castanheira-dogurgueia (Dipteryx lacunifera Ducke), esses estudos são ainda mais raros, a despeito da importância dessas espécies para a sobrevivência da fauna silvestre e do seu uso alimentar e, muitas vezes, medicinal pelas populações locais (ABDALA et al., 2002).

A castanheira-do-gurgueia é uma espécie que apresenta vasta ocorrência natural no cerrado do sudoeste piauiense, onde seus frutos e castanhas são comercializados em feiras livres da região, especialmente no município de Bom Jesus. Além da castanha, rica em proteínas, lipídios e minerais (CARVALHO, 2008; CARVALHO et al., 2008), tornando-a interessante para o consumo humano, suas árvores fornecem sombra e alimento para o gado no período de maior escassez na região.

A obtenção de genótipos com características agronômicas de interesse inicia-se com a manipulação dos recursos genéticos vegetais, sendo a variabilidade genética o ponto de partida de qualquer programa de melhoramento genético de uma espécie. A caracterização dessa variabilidade é importante aos estudos de fitomelhoramento. Deste modo, as técnicas multivariadas têm-se mostrado úteis, por avaliar o indivíduo em vários aspectos e proporcionar uma visão holística de cada genótipo (CRUZ et al., 2004). Dentre elas, as medidas de dissimilaridade têm sido empregadas, com frequência, na interpretação da divergência genética, com base em caracteres morfológicos e agronômicos em plantas perenes (ARAÚJO et al., 2002; MOURA et al., 2005; OLIVEIRA, et al., 2007). Em castanheira-do-gurgueia, ainda não há relatos na literatura especializada sobre estudos de divergência genética. Nessa perspectiva, e considerando a importância da espécie, cujo extrativismo tem relevância para a alimentação do sertanejo, além de constituir-se numa importante fonte de renda, faz-se necessária a realização de estudos que possam contribuir para o seu manejo adequado.
Dessa forma, o presente trabalho teve como objetivo avaliar a divergência genética entre 23 genótipos de castanheira-do-gurgueia, com base em características físicas e químico-nutricionais do fruto.

\section{MATERIAL E MÉTODOS}

Os frutos de 23 genótipos de castanheira-dogurgueia (Tabela 1) foram obtidos, em setembro de 2008, em populações naturais, em três municípios do cerrado do sudoeste piauiense, localizados na microrregião do Alto-Médio Gurgueia: Bom Jesus (0904'13" S, 44²1'28" W e 277m), Alvorada do Gurgueia $\left(08^{\circ} 25^{\prime} 28^{\prime \prime} \mathrm{S}, 43^{\circ} 46^{\prime} 38^{\prime}\right.$ " W e $\left.281 \mathrm{~m}\right)$ e Palmeira do Piauí $\left(08^{\circ} 43^{\prime} 35^{\prime}\right.$ 'S, $44^{\circ} 14^{\prime} 30^{\prime \prime}$ W e 270 $\mathrm{m})$. A amostragem foi realizada em função da disponibilidade de frutos maduros por ocasião da coleta.

Nas avaliações físicas e químico-nutricionais do fruto, foi utilizada uma amostra de 10 frutos por genótipo, sendo cada fruto com uma castanha. Foram medidas as seguintes características físicas: (a) fruto - massa média (MMF); comprimento (CF); largura (LF); espessura (EF), e massa média do pericarpo (MMP); e (b) castanha - massa média (MMC); comprimento (CC); largura (LC), e espessura (EC). As medidas da massa foram realizadas em balança digital de precisão e expressas em gramas. As medidas de comprimento e espessura foram realizadas com um paquímetro digital e foram expressas em milímetros. A extração das castanhas foi realizada manualmente, usando-se um torno.

Após as análises físicas, as castanhas foram secas em estufa, com circulação forçada de $\operatorname{ar}\left(60^{\circ} \mathrm{C}\right)$, por 24 horas. Em seguida, as castanhas foram trituradas em um multiprocessador. Logo após, as amostras foram acondicionadas em embalagens plásticas, etiquetadas e armazenadas em temperatura ambiente até o início das análises químico-nutricionais.

As seguintes análises químico-nutricionais da castanha foram realizadas: gordura $(\mathrm{G})$; fibra bruta (FB); proteína bruta (PB); cinzas (CZ); energia (E); carboidratos totais $(\mathrm{CT})$, e minerais $(\mathrm{Ca}, \mathrm{P}, \mathrm{K}, \mathrm{Mg}$, $\mathrm{Cu}, \mathrm{Mn}, \mathrm{Zn}$ e Fe). Os teores de G, FB, PB e CZ foram determinados pelos métodos descritos nas normas analíticas da AOAC (1992) e expressos em percentagem. A determinação do teor de $\mathrm{G}$ foi efetuada em extrator de Soxhlet, utilizando-se de éter de petróleo como solvente. $\mathrm{O}$ teor proteico consistiu na avaliação do nitrogênio total. $\mathrm{O}$ teor de nitrogênio total da amostra multiplicado por 6,25 resultou no teor de proteína bruta. $\mathrm{O}$ teor de cinzas foi determinado pelo método de aquecimento ao rubro AOAC (1992). $O$ valor energético foi calculado pela fórmula: 
$\mathrm{E}=$ proteína bruta $(\mathrm{g}) \times 4 \mathrm{kcal}+$ carboidratos totais $(\mathrm{g})$ x $9 \mathrm{kcal}+$ gordura (g) x 4 kcal (KOZIOL; PEDERSEN, 1993) e expresso em kcal $100 \mathrm{~g}^{-1}$. O teor de CT foi obtido pela fórmula $\mathrm{CT}=100-(\%$ proteína bruta $+\%$ fibra bruta $+\%$ gordura). Os teores de minerais foram determinados pelo método de espectrofotometria de absorção atômica, de acordo com IAL (2005) e expressos em mg $100 \mathrm{~g}^{-1}$.

Nas determinações físicas, o delineamento estatístico foi inteiramente ao acaso, com 23 tratamentos (genótipos), onde 10 frutos e 10 castanhas por genótipo foram utilizados como repetições. Nas determinações químico-nutricionais, o delineamento estatístico também foi inteiramente ao acaso, com 23 tratamentos (genótipos), só que, neste caso, com três repetições de 10 castanhas trituradas por genótipo.

Inicialmente, realizou-se a análise de variância para estimar a variabilidade entre os genótipos para os caracteres em estudo e também a análise de resíduos com a finalidade de verificar se as pressuposições da análise de variância foram atendidas. Em seguida, as análises de divergência genética foram realizadas, utilizando-se da distância generalizada de Mahalanobis $\left(\mathrm{D}^{2}\right)$ como medida de dissimilaridade entre todos os pares de genótipos, sendo a importância relativa dos caracteres estimada pelo método de Singh (1981). Os métodos de agrupamento utilizados foram de Tocher e UPGMA (Unweighted Pair Group Method Arithmetic Average).

Os dados foram padronizados, e as análises estatísticas foram processadas, utilizando o recurso computacional Genes versão 2007 (CRUZ, 2009).

\section{RESULTADOS E DISCUSSÃO}

$\mathrm{O}$ teste $\mathrm{F}$ indicou diferenças significativas $(\mathrm{P}<0,01)$ entre os genótipos para todas as características físicas e a maioria dos caracteres químico-nutricionais analisados, exceto para teor de $\mathrm{Ca}$ (Tabela 2), evidenciando a existência de variabilidade genética no germoplasma estudado, bem como a perspectiva de ganhos genéticos por meio da seleção para um ou mais caracteres de interesse. Em geral, os genótipos apresentaram características desejáveis, como comprimento de fruto $(\mathrm{CF})(38,11 \mathrm{~mm})$, de castanha (CC) $(23,39 \mathrm{~mm}), \mathrm{P}\left(361,17 \mathrm{mg} 100 \mathrm{~g}^{-1}\right), \mathrm{K}(939,42$ $\left.\mathrm{mg} 100 \mathrm{~g}^{-1}\right), \mathrm{Mg}\left(171,86 \mathrm{mg} 100 \mathrm{~g}^{-1}\right)$, proteína bruta (PB) $(15,41 \%)$, gordura $(\mathrm{G})(45,63 \%)$, carboidratos totais CT $(34,28 \%)$ e energia (E) $(552,68 \mathrm{kcal} 100 \mathrm{~g}$ $\left.{ }^{1}\right)$, mas exibiram baixo valor quanto à massa média de castanha (MMC) $(0,95 \mathrm{~g})$, indicando que, se o intuito for tornar a espécie cultivada, esse último caráter precisa ser melhorado. Os resultados de PB,
G e CT, na castanha, foram similares àqueles obtidos por Carvalho et al. (2008) para a castanha da mesma espécie; já os de FB e cinzas (CZ) foram inferiores aos obtidos por esses autores.

Em comparação com outros tipos de castanha, os resultados obtidos neste estudo mostram que a castanha-do-gurgueia é uma boa fonte de $\mathrm{P}, \mathrm{K}, \mathrm{Mg}$, $\mathrm{PB}, \mathrm{FB}, \mathrm{CT}$ e E. Por exemplo, em PB, é superior ao teor obtido por Crepaldi et al. (2001) para a castanha de licuri (Syagrus coronata Martius) (11,5\%); em FB, é superior ao teor médio de $2,2 \%$ obtido por Lima et al. (2007) para a castanha de pequi; em CT, os resultados são equivalentes ao encontrado por Carvalho et al. (2008) para a castanha da mesma espécie $(36,2 \%)$ e bem inferior para a castanha de sapucaia (Lecythis pisonis Camb.) (11,1\%); em CZ, o teor médio está um pouco acima daqueles obtidos por Carvalho et al. (2008) também para castanha-dogurgueia (2,5\%), Lima et al. (2004), para castanha de caju (Anacardium occidentale L.) (2,5\%), TACO (2006) para amendoim (Arachis hypogaea L.) (2,2\%) e noz-europeia (Prunus sp.) $(2,1 \%)$; e em E, o teor ficou um pouco acima do obtido por Carvalho (2008) para a castanha de chichá (Sterculia striata St. Hil. et Naud) (499,2 kcal $\left.100 \mathrm{~g}^{-1}\right)$. No entanto, a castanhado-gurgueia é pouco rica em PB quando comparada com castanha de caju (24,5\%) (LIMA et al., 2004), amendoim $(27,2 \%)$ (TACO, 2006) e castanha de pequi $(25,3 \%)$ (LIMA et al., 2007).

Em termos médios, o conteúdo de FB obtido neste trabalho está abaixo daquele encontrado por Souza et al. (2008) para a castanha de sapucaia (7,0\%), por Taco (2006) para a castanha-do-brasil (Bertholletia excelsa H.B.K) (7,9\%). Carvalho et al. (2008) obtiveram, em chichá, teor médio de CT $(45,1 \%)$ bem superior ao obtido no presente trabalho. $\mathrm{O}$ teor de cinza é inferior aos teores médios relatados por Carvalho et al. (2008) para as castanhas de chichá $(3,2 \%)$ e sapucaia $(3,4 \%)$ e por Souza et al. (2008) para a sapucaia (3,1\%). Já em E, os resultados obtidos neste trabalho são equivalentes aos obtidos por Carvalho (2005) para castanha da

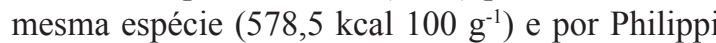
(2003) para castanha de caju $\left(574,0 \mathrm{kcal} 100 \mathrm{~g}^{-1}\right)$, e inferiores aos relatados para castanha-do-brasil

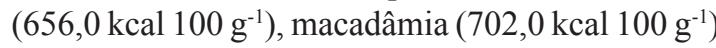
e noz-pecã (667,0 kcal $\left.100 \mathrm{~g}^{-1}\right)$ (PHILIPPI, 2003),

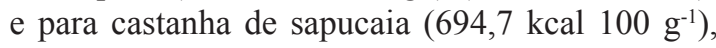
(CARVALHO, 2005).

Os teores médios de $\mathrm{P}\left(361,17 \mathrm{mg} 100 \mathrm{~g}^{-1}\right)$, $\mathrm{K}\left(939,42 \mathrm{mg} 100 \mathrm{~g}^{-1}\right)$ e $\mathrm{Mg}\left(171,86 \mathrm{mg} 100 \mathrm{~g}^{-1}\right)$ (Tabela 2) obtidos neste estudo foram superiores aos relatados para a castanha de baru (Takemoto et al., 2001). Porém, foram inferiores aos obtidos por 
Souza et al. (2008) para castanha de sapucaia, por Taco (2006) para castanha-do-brasil e por Paiva et al. (2000) para a castanha-de-caju.

No que se refere aos micronutrientes, os teores médios de $\mathrm{Cu}\left(1,24 \mathrm{mg} 100 \mathrm{~g}^{-1}\right)$, Mn $(9,47$ mg $\left.100 \mathrm{~g}^{-1}\right), \mathrm{Zn}\left(3,82 \mathrm{mg} 100 \mathrm{~g}^{-1}\right)$ e Fe $(4,92 \mathrm{mg}$ $100 \mathrm{~g}^{-1}$ ) (Tabela 2) foram, em geral, inferiores aos relatados na literatura para diversos tipos de castanha (TAKEMOTO et al., 2001; CARVALHO, 2005; SOUZA et al., 2008).

As características físicas e químico-nutricionais que mais contribuíram para a divergência entre os genótipos estudados foram massa média do pericarpo (MMP) $(42,37 \%)$, massa média de fruto (MMF) $(38,92 \%)$, energia (E) $(5,22 \%)$, fibra bruta (FB), $(4,87 \%)$, carboidratos totais (CT) $(1,56 \%)$ e proteína bruta (PB) $(1,29 \%)$ (Tabela 3). A MMP e a MMF foram as mais eficientes em explicar a dissimilaridade entre os genótipos, devendo ser priorizada na escolha de genitores em futuros estudos com a espécie. Em umbu-cajazeira (Spondia spp.), Santos et al. (2008) observaram que, além da massa média do fruto, o comprimento e o diâmetro do fruto e a massa da polpa tiveram as maiores contribuições para a divergência genética. Ressaltaram, contudo, a importância de se avaliar outros caracteres agronômicos, especialmente quando se pensa no melhoramento genético e na formação de bancos de germoplasma. No entanto, as características químico-nutricionais são importantes e merecem melhor atenção em estudos futuros com a espécie.

O método de agrupamento Tocher permitiu a formação de nove grupos distintos de genótipos (Tabela 4), confirmando a presença de variabilidade no germoplasma estudado, detectada pela análise de variância (Tabela 2). O grupo I reuniu o maior número de genótipos (G-3, G-16, G-1, G-5, G-21, G-8, G-7), demonstrando que eles são pouco variáveis entre si. Os genótipos reunidos no grupo I são de várias localidades, sobressaindo os oriundos dos povoados de Pitombeira e Pati, no município de Bom Jesus (Tabela 1). Em geral, os agrupamentos entre os genótipos indicam pouca relação com local de ocorrência. Siqueira et al. (1993) sugerem que a baixa diversidade entre populações de locais distintos pode ser devida à sua origem a partir de uma população ancestral comum, ou, ainda, que essas populações possam ter sofrido ação antrópica, dispersão de frutos via animais e polinização cruzada.

Os grupos II, III e IV foram formados por três genótipos cada, sendo do grupo II os genótipos G-9, G-20 e G-17, o primeiro e o terceiro do povoado Pati e o segundo do povoado Porteiras, todos no município de Bom Jesus; do grupo III, os genótipos G-11 (Pov. Pati), G-12 (Pov. Corrente) e G-19 (Pov. Porteiras), e do grupo IV, os genótipos G-4 (Pov. Pitombeira), G-23 (Pov. Boa Sorte) e G-10 (Pov. Pati). Os grupos V e VI foram formados por dois genótipos cada, sendo do grupo $\mathrm{V}$, os genótipos G-6 e G-13, procedentes dos povoados Pitombeira e São Gonçalo, e do grupo VI, os genótipos G-2 (Campo Experimental da Embrapa Meio-Norte), no município de Alvorada-do-Gurgueia e G-18 (Pov. Santa Teresa) (Tabela 1). Por sua vez, os grupos VII, VIII e IX foram formados apenas por um genótipo cada: G-22, G-14 e G-15, respectivamente, sendo o genótipo G-22 proveniente do povoado Pati; o G-14, do povoado Estreito, e o G-15, do povoado Vereda Seca (Tabela 1).

No método de Tocher, um indivíduo ainda não agrupado só é incluído em determinado grupo se sua distância média em relação a esse grupo não ultrapassar determinado valor preestabelecido, sendo que esse valor, geralmente, é tomado como a maior amplitude do conjunto das menores estimativas de distância que envolvem cada um dos indivíduos em agrupamento (CRUZ; CARNEIRO, 2003). Com base nisso, constata-se que a divergência dos genótipos, G-14, G-15 e G-22 em relação aos demais, é elevada, o que fez com que esses genótipos não se agrupassem com nenhum outro.

O número de grupos formados pelo método de Tocher evidencia a ampla variabilidade entre os genótipos analisados. Araujo et al. (2002), avaliando características físicas de frutos de 27 acessos de cupuaçuzeiro também observaram ampla variabilidade entre eles, detectada pelo agrupamento Tocher. Ainda em cupuaçu, Alves (2002) avaliou 31 acessos com base em descritores botânico-agronômicos e verificou a formação de seis grupos pelo método de Tocher.

O agrupamento dos genótipos pelo método UPGMA (Figura 1), com base na dissimilaridade genética média $\left(d g_{m}=62 \%\right)$, mostra a formação de três grupos distintos. Os genótipos mais divergentes foram G-17 e G-18, e os mais similares foram G-3 e G-16. O corte no dendrograma (31\%) com base na observação de pontos com alta mudança de nível, conforme a recomendação de Cruz e Regazzi (1997) e Cruz e Carneiro (2003), evidenciou-se a formação de 10 grupos (Figura 1) com características semelhantes aos obtidos pelo método de Tocher (Tabela 4). Assim como no método de Tocher, o método UPGMA também não organizou os genótipos por local de coleta, o que novamente reforça a evidência de divergência entre genótipos de mesma procedência. Cruzamentos entre os genótipos mais divergentes podem proporcionar aumento na variabilidade e, 
possivelmente, a obtenção de indivíduos superiores.

Os métodos de otimização Tocher e de hierarquização UPGMA são normalmente empregados em conjunto, para completar os resultados e auxiliar numa melhor distinção dos agrupamentos formados. O emprego de mais de um método de agrupamento, em razão das diferenças na hierarquização, otimização e ordenação dos grupos, permite que a classificação deles se complemente em função dos critérios que cada técnica utiliza, e impede que inferências errôneas sejam adotadas na alocação de elementos, dentro de um determinado subgrupo de genótipos (ARRIEL et al., 2006).
Desta forma, considerando os grupos de genótipos formados pelos métodos de Tocher (Tabela 4) e UPGMA (Figura 1), é possível inferir que cruzamentos entre os genótipos G-3 e G-16 com o genótipo G-22, dos genótipos G-14 e G-15 com o genótipo G-18, e do genótipo G-22 com o genótipo G-17, constituem boas alternativas para obtenção de populações segregantes para uso em estudos genéticos e em futuros trabalhos de melhoramento genético da espécie.

TABELA 1 - Localização geográfica de 23 genótipos de castanheira-do-gurgueia coletados no cerrado do sudoeste Piauiense.

\begin{tabular}{|c|c|c|c|c|c|}
\hline Genótipos & Local de coleta & Município & Altitude $(\mathrm{m})$ & Latitude & Longitude \\
\hline G-1 & C. E. Embrapa Meio-Norte & Alvorada do Gurgueia & 248 & $08^{\circ} 26^{\prime} 29^{\prime \prime}$ & $43^{\circ} 52^{\prime} 19^{\prime \prime}$ \\
\hline $\mathrm{G}-2$ & C. E. Embrapa Meio-Norte & Alvorada do Gurgueia & 251 & $08^{\circ} 26^{\prime} 29^{\prime \prime}$ & $43^{\circ} 52^{\prime} 19^{\prime \prime}$ \\
\hline G-3 & Pov. Pitombeira & Bom Jesus & 328 & $09^{\circ} 16^{\prime} 14^{\prime \prime}$ & $44^{\circ} 16^{\prime} 28^{\prime \prime}$ \\
\hline G-4 & Pov. Pitombeira & Bom Jesus & 339 & $09^{\circ} 16^{\prime} 17^{\prime \prime}$ & $44^{\circ} 16^{\prime} 44^{\prime \prime}$ \\
\hline G-5 & Pov. Pitombeira & Bom Jesus & 323 & $09^{\circ} 16^{\prime} 18^{\prime \prime}$ & $44^{\circ} 16^{\prime} 44^{\prime \prime}$ \\
\hline G-6 & Pov. Pitombeira & Bom Jesus & 369 & $09^{\circ} 15^{\prime} 58^{\prime \prime}$ & $44^{\circ} 15^{\prime} 57^{\prime \prime}$ \\
\hline G-7 & Pov. Pati & Bom Jesus & 341 & $09^{\circ} 11^{\prime} 07^{\prime \prime}$ & $44^{\circ} 14^{\prime} 34^{\prime \prime}$ \\
\hline G-8 & Pov. Pati & Bom Jesus & 329 & $09^{\circ} 12^{\prime} 03^{\prime \prime}$ & $44^{\circ} 13^{\prime} 56^{\prime \prime}$ \\
\hline G-9 & Pov. Pati & Bom Jesus & 333 & $09^{\circ} 12^{\prime} 02^{\prime \prime}$ & $44^{\circ} 13^{\prime} 57^{\prime \prime}$ \\
\hline G-10 & Pov. Pati & Bom Jesus & 335 & $09^{\circ} 12^{\prime} 25^{\prime \prime}$ & $44^{\circ} 13^{\prime} 00^{\prime \prime}$ \\
\hline G-11 & Pov. Pati & Bom Jesus & 342 & $09^{\circ} 12^{\prime} 28^{\prime \prime}$ & $44^{\circ} 12^{\prime} 60^{\prime \prime}$ \\
\hline G-12 & Pov. Corrente & Bom Jesus & 340 & $09^{\circ} 11^{\prime} 26^{\prime \prime}$ & $44^{\circ} 32^{\prime} 04^{\prime \prime}$ \\
\hline G-13 & Pov. São Gonçalo & Bom Jesus & 308 & $09^{\circ} 10^{\prime} 29^{\prime \prime}$ & $44^{\circ} 33^{\prime} 19^{\prime \prime}$ \\
\hline G-14 & Pov. Estreito & Bom Jesus & 323 & $09^{\circ} 09^{\prime} 45^{\prime \prime}$ & $44^{\circ} 34^{\prime} 46^{\prime \prime}$ \\
\hline G-15 & Pov. Vereda Seca & Bom Jesus & 328 & $09^{\circ} 09^{\prime} 21^{\prime \prime}$ & $44^{\circ} 35^{\prime} 31^{\prime \prime}$ \\
\hline G-16 & Pov. Escalvado & Bom Jesus & 341 & $09^{\circ} 09^{\prime} 07^{\prime \prime}$ & $44^{\circ} 37^{\prime} 33^{\prime \prime}$ \\
\hline G-17 & Pov. Pati & Bom Jesus & 324 & $09^{\circ} 11^{\prime} 23$ '” & $44^{\circ} 14^{\prime} 14^{\prime \prime}$ \\
\hline G-18 & Pov. SantaTeresa & Bom Jesus & 340 & $09^{\circ} 12^{\prime} 32^{\prime \prime}$ & $44^{\circ} 13^{\prime} 07^{\prime \prime}$ \\
\hline G-19 & Pov. Porteiras & Bom Jesus & 350 & $09^{\circ} 11^{\prime} 28^{\prime \prime}$ & $44^{\circ} 13^{\prime} 24^{\prime \prime}$ \\
\hline G-20 & Pov. Porteiras & Bom Jesus & 334 & $09^{\circ} 11^{\prime} 31^{\prime \prime}$ & $44^{\circ} 13^{\prime} 39^{\prime \prime}$ \\
\hline G-21 & Pov. Porteiras & Bom Jesus & 332 & $09^{\circ} 11^{\prime} 27^{\prime \prime}$ & $44^{\circ} 13^{\prime} 43^{\prime \prime}$ \\
\hline G-22 & Pov. Pati & Bom Jesus & 332 & $09^{\circ} 11 ' 33$ '” & $44^{\circ} 13^{\prime} 55^{\prime \prime}$ \\
\hline G-23 & Pov. Boa Sorte & Palmeira do Piauí & 293 & $08^{\circ} 42^{\prime} 40^{\prime \prime}$ & $44^{\circ} 15^{\prime} 12^{\prime \prime}$ \\
\hline
\end{tabular}

C.E: Campo experimental e Pov.: Povoado. 
TABELA 2 - Resumo da análise de variância para características físicas do fruto e químico-nutricionais da castanha em 23 genótipos de castanheira-do-gurgueia de ocorrência natural no cerrado do sudoeste piauiense.

\begin{tabular}{|c|c|c|c|c|}
\hline Características $^{1}$ & QM (genótipos) & QM (resíduo) & Média & $\mathrm{CV}(\%)$ \\
\hline \multicolumn{5}{|c|}{-------------------------- Características físicas do fruto --------------------------- } \\
\hline MMF (g) & $307,09 * *$ & 10,7613 & 15,76 & 20,81 \\
\hline MMP (g) & $285,62 * *$ & 10,1310 & 14,81 & 21,49 \\
\hline $\mathbf{C F}(\mathbf{m m})$ & $159,46^{* *}$ & 8,7260 & 38,11 & 7,75 \\
\hline LF (mm) & $130,23 * *$ & 5,3892 & 33,78 & 6,87 \\
\hline $\mathbf{E F}(\mathbf{m m})$ & $77,14 * *$ & 2,5375 & 22,38 & 7,12 \\
\hline MMC (g) & $0,74 * *$ & 0,0284 & 0,95 & 17,72 \\
\hline $\mathrm{CC}(\mathrm{mm})$ & $49,27 * *$ & 2,7278 & 23,39 & 7,06 \\
\hline $\mathbf{L C}(\mathbf{m m})$ & $23,63 * *$ & 1,2839 & 13,49 & 8,40 \\
\hline $\mathbf{E C}(\mathbf{m m})$ & $5,78^{* *}$ & 0,2460 & 4,79 & 10,35 \\
\hline \multicolumn{5}{|c|}{ Características químico-nutricionais da castanha } \\
\hline$P\left(m g 100 g^{-1}\right)$ & $8692,44 * *$ & 370,15 & 361,17 & 5,33 \\
\hline $\mathrm{K}\left(\mathrm{mg} 100 \mathrm{~g}^{-1}\right)$ & $80391,37 * *$ & 8092,74 & 939,42 & 9,58 \\
\hline $\operatorname{Mg}\left(\operatorname{mg} 100 \mathrm{~g}^{-1}\right)$ & $4304,19 * *$ & 470,07 & 171,86 & 12,62 \\
\hline $\mathrm{Cu}\left(\mathrm{mg} 100 \mathrm{~g}^{-1}\right)$ & $0,57 * *$ & 0,02 & 1,24 & 11,00 \\
\hline $\operatorname{Mn}\left(\operatorname{mg} 100 \mathrm{~g}^{-1}\right)$ & $225,93 * *$ & 2,28 & 9,47 & 15,96 \\
\hline $\mathrm{Zn}\left(\operatorname{mg} 100 \mathrm{~g}^{-1}\right)$ & $1,32 * *$ & 0,33 & 3,82 & 15,08 \\
\hline $\mathrm{Fe}\left(\mathrm{mg} 100 \mathrm{~g}^{-1}\right)$ & $3,62 * *$ & 0,40 & 4,92 & 12,80 \\
\hline PB (\%) & $5,52 * *$ & 0,33 & 15,41 & 3,73 \\
\hline G (\%) & $11,60 * *$ & 3,38 & 45,63 & 4,03 \\
\hline FB $(\%)$ & $1,03 * *$ & 0,19 & 4,68 & 9,37 \\
\hline CZ (\%) & $0,17 * *$ & 0,03 & 2,68 & 6,42 \\
\hline CT (\%) & $12,74 * *$ & 3,87 & 34,28 & 5,74 \\
\hline E (kcal 100 g-1) & $349,15 * *$ & 111,64 & 552,68 & 1,91 \\
\hline
\end{tabular}

** Significativo a $1 \%$ pelo teste $\mathrm{F}$.

${ }^{1}$ MMF: Massa média do fruto; MMP: Massa média do pericarpo; CF: Comprimento do fruto; LF: Largura do fruto; EF: Espessura do fruto; MMC: Massa média da castanha; CC: Comprimento da castanha; LC: Largura da castanha; EC: Espessura da castanha; PB: Proteína bruta; G: Gordura; FB: Fibra bruta; CZ: Cinzas; CT: Carboidratos totais e E: Energia. 
TABELA 3 - Contribuição relativa das características físicas do fruto e químico-nutricionais da castanha para divergência genética entre 23 genótipos de castanheira-do-gurgueia de ocorrência natural no cerrado do sudoeste piauiense, pelo método de SINGH (1981).

\begin{tabular}{ccc}
\hline Características $^{1}$ & S.j & \\
\hline------------------ \\
MMF & 1950990.946 & 38,92 \\
CF & 13372.679 & 0,27 \\
LF & 39625.647 & 0,79 \\
EF & 25885.845 & 0,52 \\
MMP & 2123874.202 & 42,37 \\
MMC & 30335.696 & 0,61 \\
CC & 4387.593 & 0,09 \\
LC & 244.858 & 0,01 \\
EC & 1828.481 & 0,04 \\
Ca & 1487.528 & 0,03 \\
P & 25113.801 & 0,50 \\
K & 15997.797 & 0,32 \\
Mg & 15683.541 & 0,31 \\
Cu & 38045.133 & 0,76 \\
Mn & 43341.088 & 0,86 \\
Zn & 790.208 & 0,02 \\
Fe & 16057.445 & 0,32 \\
PB & 64861.021 & 1,29 \\
G & 15159.866 & 0,30 \\
FB & 243896.911 & 4,87 \\
CZ & 1938.650 & 0,04 \\
CT & 78415.848 & 1,56 \\
E & 261418.468 & 5,22 \\
\hline
\end{tabular}

${ }^{1}$ MMF: Massa média do fruto; MMP: Massa média do pericarpo; CF: Comprimento do fruto; LF: Largura do fruto; EF: Espessura do fruto; MMC: Massa média da castanha; CC: Comprimento da castanha; LC: Largura da castanha; EC: Espessura da castanha; PB: Proteína bruta; G: Gordura; FB: Fibra bruta; CZ: Cinzas; CT: Carboidratos totais e E: Energia.

TABELA 4 - Agrupamento de 23 genótipos de castanheira-do-gurgueia de ocorrência natural no cerrado do sudoeste piauiense, com base em características físicas do fruto e químico-nutricionais da castanha, pelo método de Tocher, utilizando a distância generalizada de Mahalanobis como medida de dissimilaridade.

\begin{tabular}{cl}
\hline Grupos & \multicolumn{1}{c}{ Genótipos } \\
\hline I & G-3, G-16, G-1, G-5, G-21, G-8, G-7 \\
II & G-9, G-20, G-17 \\
III & G-11, G-12, G-19 \\
IV & G-4, G-23, G-10 \\
V & G-6, G-13 \\
VI & G-2, G-18 \\
VII & G-22 \\
VIII & G-14 \\
IX & G-15 \\
\hline
\end{tabular}




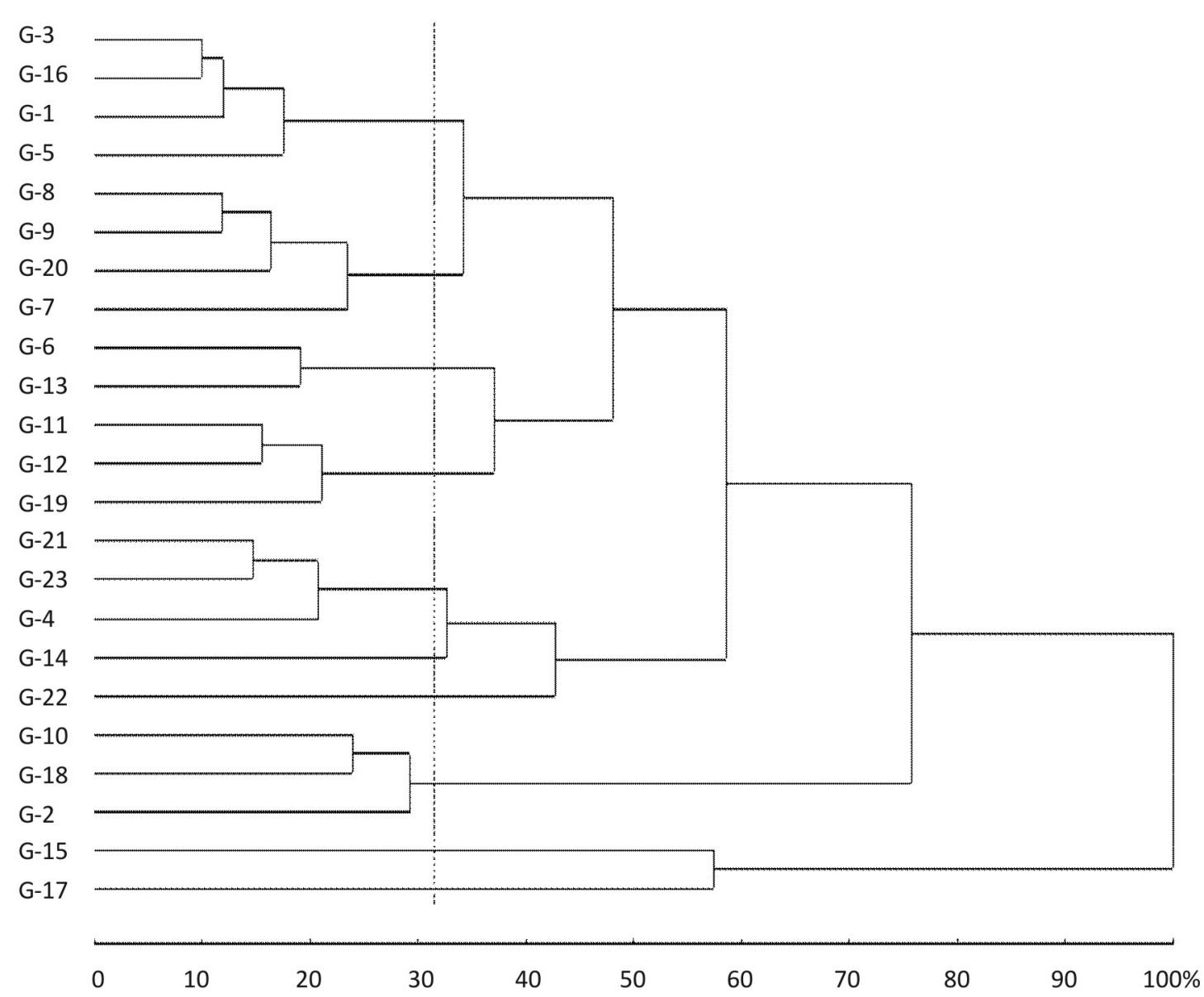

FIGURA 1 - Dendrograma resultante da análise de 23 genótipos de castanheira-do-gurgueia, de ocorrência natural no cerrado do sudoeste piauiense, com base em características físicas do fruto e químico-nutricionais da castanha, pelo método de agrupamento UPGMA, utilizando a distância generalizada de Mahalanobis como medida de dissimilaridade.

\section{CONCLUSÕES}

1 - Há variabilidade genética entre os genótipos de castanheira-do-gurgueia avaliados.

2 - Os genótipos G-17 e G-18 são os mais divergentes, e os genótipos G-3 e G-16 são os mais similares.

3- As características que mais contribuem para a divergência entre os genótipos são MMP, MMF, E, FB, CT e PB.

4- Os métodos de otimização Tocher e de hierarquização UPGMA são complementares na formação dos agrupamentos.

5 - A castanha-do-gurguéia é uma boa fonte de $\mathrm{P}, \mathrm{K}, \mathrm{Mg}, \mathrm{PB}, \mathrm{FB}, \mathrm{CT}$ e E.

\section{AGRADECIMENTOS}

À CAPES, pela concessão da bolsa de Mestrado, à Embrapa Meio-Norte e à Universidade Federal do Piauí - UFPI, pela possibilidade de realizar as análises físicas e químico-nutricionais.

Ao Dr. Valdomiro Aurélio Barbosa de Souza (in memoriam), pela orientação valiosa e pela iniciação no campo da pesquisa.

\section{REFERÊNCIAS}

ABDALA, L.; MORAES, M.L.T. de; RECHIA, C.G.V.; GIORGINI, J.F.; SÁ, M.E. de; POLIZELI, M. de L.T. de M. Biochemical traits useful for the determination of genetic variation in a natural population of Myracrodruon urundeuva. Pesquisa Agropecuária Brasileira, Brasilia, v.37, n.7, p.909916, 2002. 
ALVES, R.M. Caracterização genética de populações de cupuaçuzeiro, Theobroma grandiflorum (Willd. ex. Spreng.) Schum., por marcadores microssatélites e descritores botânico-agronômicos. 2002. 159f. Tese (Doutorado em Agronomia: Genética e Melhoramento de Plantas) - Escola Superior de Agricultura Luiz de Queiroz, Universidade de São Paulo, Piracicaba, 2002.

AOAC. Association of Official Analytical Chemists. Official methods of analysis. $12^{\text {th }}$ ed. Washington, 1992. 1115p.

ARAUJO, D.G. de; CARVALHO, S.P.; ALVES, R.M. Divergência genética entre clones de cupuaçuzeiro (Theobroma grandiflorum Willd ex Spreng Schum). Ciência e Agrotecnologia, Lavras, v.26, n.1, p.13-21, 2002.

ARRIEL, N.H.C.; MAURO, A.O.D.; MAURO, S.M.Z.D.; BAKKE, O.A.; UNÊDA-TREVISOLI, S.H.; COSTA, M.M.; CAPELOTO, A.; CORRADO, A.R. Técnicas multivariadas na determinação da diversidade genética em gergelim usando marcadores RAPD. Pesquisa Agropecuária Brasileira, Brasília, v.41, n.5, p.801-809, 2006.

CARVALHO, M.G. de. Barras de cereais com amêndoas de chichá, sapucaia e castanha-dogurgueia, complementadas com casca de abacaxi. 2008. 92f. Dissertação (Mestrado em Tecnologia de Alimentos) - Universidade Federal do Ceará, Fortaleza, 2008.

CARVALHO, M.G. de. Caracterização nutricional de nozes de chichá, castanha-do-gurgueia e sapucaia, in natura e torradas. 2005. 41f. Monografia (Trabalho de Graduação em Tecnólogo em Alimentos) - Centro Federal de Educação Tecnológica, Teresina, 2005

CARVALHO, M.G. de; COSTA, J.M.C. da; SOUZA, V.A.B.; MAIA, G.A. Avaliação dos parâmetros físicos e nutricionais de amêndoas de chichá, sapucaia e castanha-do-gurgueia. Revista Ciência Agronômica, Fortaleza, v.39, n.4, p.517-523, 2008.

CREPALDI, I.C.; ALMEIDA-MURADIAN, L.B. de; RIOS, M.D.G.; PENTEADO, M. de V.C.; SALATINO, A. Composição nutricional do fruto de licuri (Syagrus coronata Martius) Beccari). Revista Brasileira de Botânica, São Paulo, v.24, n.2, p.155159, 2001
CRUZ, C.D. Programa genes: aplicativo computacional em genética e estatística. Versão 2007. Disponível em: <http://www.ufv.br/dbg/genes/genes.htm>. Acesso em: 10 mar. 2009. CRUZ, C.D.; REGAZZI, A.J. Modelos biométricos aplicados ao melhoramento genético. 3.ed. Viçosa: UFV, 1997. v.1, 480 p.

CRUZ, C.D.; CARNEIRO, P.C.S. Modelos biométricos aplicados ao melhoramento genético. Viçosa: UFV, 2003. v.2. 585p.

CRUZ, C.D.; REGAZZI, J.A.; CARNEIRO, P.C.S. Divergência genética. In: CRUZ, C.D.; REGAZZI, J.A.; CARNEIRO, P.C.S. (Ed.). Modelos biométricos aplicados ao melhoramento genético. Viçosa: UFV, 2004. v.1, p.377-413.

IAL - Instituto Adolfo Lutz. Métodos físico-químicos para análise de alimentos. 4.ed. São Paulo: IAL, 2005. 1015p.

KOZIOL, M.J.; PEDERSEN, H.B. Phytelephas aequatorialis Spruce (Arecaceae) in human and animal nutrition. Economic Botany, Bornx, v.47, p.401-407, 1993.

LIMA, A.C.; GARCIA, N.H.P.; LIMA, J.R. Obtenção e caracterização dos principais produtos do caju. Boletim do Centro de Pesquisa de Processamento de Alimentos, Curitiba, v.22, n.1, p.133-144, 2004.

LIMA, A. de; SILVA, A.M. de O. e; TRINDADE, R.A.; TORRES, R.P.; MANCINI FILHO, J. Composição química e compostos bioativos presentes na polpa e na amêndoa do pequi (Caryocar brasiliense Camb.). Revista Brasileira de Fruticultura, Jaboticabal, v.29, n.3, p.695-698, 2007.

MOURA, N.F.; CHAVES, L.J.; VENCOSVSKY, R.; ZUCCHI, M.I.; PINHEIRO, J.B.; MORAIS, L.K.; MOURA, M.F. Seleção de marcadores RAPD para o estudo da estrutura genética de populações de Hancornia speciosa Gomez. Bioscience Journal, Uberlândia, v.21, n.3, p.119-125, 2005.

OLIVEIRA, M. do S.P. de; FERREIRA, D.F.; SANTOS, J.B. dos. Divergência genética entre acessos de açaizeiro fundamentada em descritores morfoagronômicos. Pesquisa Agropecuária Brasileira, Brasília, v.42, n.4, p.501-506, 2007. 
PAIVA, F.F.A.; GARRUTTI, D.S.; SILVA NETO, R.M. Aproveitamento industrial do caju. Fortaleza: Embrapa Agroindústria Tropical, 2000. 88p.

PHILIPPI, S.T. Nutrição e técnica dietética. Barueri: Monole, 2003. 373p.

SANTOS, L.A. dos; DANTAS, A.C.V.L.; ALMEIDA, V. de O.; NEVES, C.G. Caracterização morfológica de umbu-cajazeira (Spondias spp.) no semirido da Bahia. In: CONGRESSO BRASILEIRO DE FRUTICULTURA, 20., 2008, Vitória. Anais... Vitória: SBF, 2008. CD-ROM.

SILVA, D.B.; SILVA, J.A.; JUNQUEIRA, N.T.V.; ANDRADE, L.R.M. Frutas do cerrado. Brasília: Embrapa Informação Tecnológica, 2001. 178p.

SINGH, D. The relative importance of characters affecting genetic divergence. Indian Journal of Genetics and Plant Breeding, New Dehli, v.41, p.237-245, 1981.
SIQUEIRA, C.M.F.; NOGUEIRA, J.C.B.; KAGEYAMA, P.Y. Conservação dos recursos genéticos ex situ do cumbaru Dipteryx alata Vog.- Leguminosae. Revista Instituto Florestal, São Paulo, v.5, n.2, p.231-243, 1993.

SOUZA, V.A.B.; CARVALHO, M.G.; SANTOS, K.S.; FERREIRA, C. da S. Características físicas de frutos e amêndoas e características químiconutricionais de amêndoas de acessos de sapucaia. Revista Brasileira de Fruticultura, Jaboticabal, v.30, n.4, p.946-952, 2008.

TACO. Tabela brasileira de composição de alimentos. 2.ed. Campinas: NEPA-UNICAMP, 2006. 113p.

TAKEMOTO, E.; OKADA, I.A.; GARBELOTTI, M.L.; TAVARES, M.; AUED-PIMENTEL, S. Composição química da semente e do óleo de baru (Dipteryx alata Vog.) nativo do município de Pirenópolis, Estado de Goiás. Revista do Instituto Adolfo Lutz, São Paulo, v.60, n.2, p.113-117, 2001. 